\title{
Percutaneous Coronary Intervention
}

National Cancer Institute

\section{Source}

National Cancer Institute. Percutaneous Coronary Intervention. NCI Thesaurus. Code C99521.

The placement of an angioplasty guide wire, balloon, or other device (e.g. stent, atherectomy, brachytherapy, or thrombectomy catheter) into a native coronary artery or coronary artery bypass graft for the purpose of mechanical coronary revascularization. 